\title{
O Acesso à justiça pública: uma experiência de Juizado de Pequenas Causas
}

\section{Introdução}

A proposta que trago à reflexão deste Seminário pode ser assim resumida:

1. Tão grave quanto o atual congestionamento burocrático do Poder Judiciário, ou mais grave ainda, é o problema da falta de acesso à Justiça por grande parte da população, em especial das camadas mais pobres e incultas.

2. As soluções convencionais de ampliação física dos serviços judiciários e de reaparelhamento material e humano da Justiça serão insuficientes, Seja para suprir o atual estado de carência em matéria de assistência judiciária, seja para atender à demanda emergente, representada pelo acréscimo acelerado de população nas regiões urbanas.

3. A criação de juizados especiais, destinados a julgar, exclusivamente, causas de reduzido valor econômico é uma das formas de minorar, a curto prazo, os graves efeitos políticos, sociais e econômicos da falta de acesso à prestação jurisdicional.

4. A experiência com juizados de pequenas causas vem obtendo razoável sucesso em outros países.

5. A viabilidade da proposta dependerá de profunda revisão de alguns conceitos tradicionais de direito processual.

A concentração urbana e a alteração nas for- mas de produção, comercialização e consumo de bens são dois fenômenos que exercem, indiscutivelmente, dramática pressão sobre os institutos tradicionais e o desempenho do Poder Judiciário. A concentração urbana - que intensifica a convivência e o intercâmbio social e econômico e amplia a demanda de fornecimento de serviços públicos essenciais - alarga a probabilidade de conflitos entre particulares e entre estes e o Estado. Por sua vez, as novas formas de produção e comercialização de bens de consumo e de bens duráveis aumentam as áreas de litígio entre produtores e comerciantes, bem como entre consumidores, de um lado, e produtores e comerciantes de outro. Nesse quadro rico e cambiante, as normas de direito substantivo rapidamente se desatualizam, em face das freqüentes mutações ocorridas nos padrões das relações jurídicas e econômicas. Simultaneamente, cresce a procura por reparação judicial e os recursos técnicos, materiaise humanos disponiveis tornam-se insuficientes para ampliar e modernizar o aparelho judiciário.

No Brasil, onde a industrialização, a mudança nos hábitos de consumo e a concentração urbana convivem com a pobreza e o despreparo cultural, o problema assume dimensão alarmante. Apesar do muito que se modernizou em matéria de legislação, ainda subsistem diversos institutos jurídicos anacrônicos, principalmente no campo do direito processual, ou mesmo simples praxes cartorárias, que são incompatíveis com o objetivo de simplificação e aceleração da justiça. 
Não pretendo, no entanto, alongar-me na análise das causas profundas dessas 'Crises do direito'. São conhecidos de todos os magistrais diagnósticos dessa crise feitos, dentre muitos outros, por George Ripert, San Tiago Dantas e Orlando Gomes. Limitar-me-ei, neste instante, a tratar da 'crise do aparelho judiciário', em particular no seu aspecto mais insidioso: a impossibilidade de acesso à prestação jurisdicional por imensa parcela da população brasileira.

A desburocratização do judiciário comporta, pelo menos, dois enfoques. Um interno, que se ocupa das causas e da eliminação do atual congestionamento do aparelho judiciário, a partir da conveniência e das necessidades da sua própria estrutura administrativa e de seus integrantes - juízes, membros do Ministério Público, advogados e serventuários. As propostas nesse sentido visam, basicamente, ao melhor aparelhamento humano e material do Judiciário e ao desestímulo ao litígio desnecessário que atravanca a justiça, principalmente de primeira instância.

O outro enfoque - o enfoque externo ocupa-se prioritariamente da ampliação do acesso à justiça, dando ênfase, portanto, às necessidades e conveniências da clientela do Judiciário. Os remédios propostos, a partir de cada um desses enfoques, coincidem em alguns pontos, mas podem divergir em outros. Sem dúvida, o aperfeiçoamento técnico, material e humano da máquina administrativa do Judiciário é essencial. Todavia é inegável também que a excessiva ênfase nas soluções internas, em especial no desestímulo ao litígio, pode conduzir a uma indesejável elitização da Justiça, mediante o agravamento desmedido dos custos judiciais para as partes.

O atual estado de carência da sociedade brasileira, no que tange à reparação de danos pelo Judiciário, está a indicar que o centro de atenção deve situar-se, com maior intensidade, nos aspectos externos do problema. Basta, para que se chegue a essa inevitável conclusão, estabelecer o perfil da clientela potencial do Judiciário nas regiões de maior concentração urbana.

Tomarei, para fins de análise, alguns dados demográficos e econômicos do Estado do Rio de Janeiro, cuja população total, em 1980, foi estimada em cerca de 11.300 .000 habitantes, dos quais $92 \%$ residem em áreas urbanas. Apenas na macrorregião do Grande Rio de Janeiro, compreendendo treze municípios, inclusive a capital, residem 8.750.000 pessoas; destas, mais de $98 \%$ encontram-seemzonas urbanas.

O acesso ao Judiciário está limitado, de um lado, pelo nível cultural do indivíduo e, de outro, pela sua condição econômica. No primeiro caso, o constrangimento decorre da incapacidade de percepção do direito violado ou dos meios disponíveis para reparação do dano; no segundo, da impossibilidade material de arcar com os custos de um litígio. Considerada, exclusivamente, a população com mais de dez anos de idade (9.250.000), verifica-se que 2.400 .000 pessoas não têm instrução ou têm até 2 anos de instrução. Do ponto de vista econômico, levando-se também em conta a população com mais de dez anos de idade, constata-se que 3.950.000 não têm rendimento, ou seja, estão fora da economia monetária e que 2.800 .000 indivíduos ganham até dois salários mínimos. Pode-se concluir, portanto, que nada menos que $57 \%$ dessa população tem remuneração mensal inferior a dezessete mil cruzeiros. Todas essas pessoas teriam, em tese, direito a pleitear assistência judiciária pela Justiça Gratuita.

No entanto, quando se examinam os dados referentes ao município do Rio de Janeiro (população: 5.100.000), verifica-se que, em 1980, foram distribuidos às Varas Cíveis da capital apenas 1.106 requerimentos de Justiça Gratuita. O próprio volume total de feitos distribuídos à Justiça Cível 64.221 - é surpreendentemente baixo em relação à população do município. Basta lembrar que na cidade de Nova lorque (7.895.563 habitantes) são apresentados anualmente, apenas perante o Juizado de Pequenas Causas, 70 mil novos pleitos de valor igual ou inferior ả hum mil dólares. No cômputo geral, nada menos que hum milhão de novas causas são submetidas, por ano, à Corte Cível daquela cidade.

Por outro lado, o custo real do litígio, tomando-se por base ainda a Justiça do município do Rio de Janeiro, revela-se insuportavelmente elevado para a maior parte da população. A cobrança de uma simples dívida ilíquida de cinqüenta mil cruzeiros implicará, para o autor, no desembolso de mais de sessenta mil cruzeiros. Se houver perícia técnica essa cifra poderá ultrapassar oitenta mil cruzeiros.

A conclusão é inevitável: seja por insúficiência cultural, seja por falta de condição econômica para enfrentar o custo da demanda, parcela ponderável da nossa pupulação urbana aproxima-se perigosamente da total desassistência judiciária.

\section{A Experiência comparada no tratamento das causas de reduzido valor}

A instituição de juizados especiais para conhecimento exclusivo de causas de pequeno valor é de origem recente, uma vez que está intimamente associada ao fenômeno da concentração urbana. Dentre as diferentes modalidades de juizados examinadas, detive-me, em particular, na experiência 
da cidade de Nova lorque, tendo em vista a semeIhança (ampliada) dos seus problemas urbanos com aqueles dos grandes centros metropolitanos brasileiros.

O Juizado das Pequenas Causas (Small Claims Court) é uma subdivisão da Corte Cível da cidade de Nova lorque, a qual, por seu turno, integra o Sistema Judiciário do Estado de Nova lorque. O Juizado opera em cinco condados (New York, Queens, Brooklin, Bronx e Richmond), sendo que, no condado de Nova lorque, por força da maior concentração populacional, se acha desdobrado em dois departamentos (Manhattan e Harlem). Tem-se, pois, como primeira e importante característica, a 'descentralização' desse serviço judiciário.

Cada Juizado é presidido por um juiz togado, com a assistência de diversos árbitros escolhidos entre advogados com ampla experiência profissional. As sessões e audiências são realizadas sempre à noite, das dezoito e trinta às vinte e uma e trinta horas, podendo todavia, estender-se até mais tarde o volume de casos assim o exigir. O Juizado de Manhattan, que é o mais ativo da cidade, funciona de segunda a quinta-feira e decide cerca de 150/170 casos por sessão.

O Juizado de Pequenas Causas tem jurisdição sobre qualquer matéria cível cujo valor não exceda a mil dólares e que possa ser liquidada, por acordo ou mediante julgamento, em dinheiro. A competência desse juizado não exclui a da Corte comum. O postulante pode, portanto, optar por submeter seu pleito à Corte Cível comum.

Somente pessoas físicas maiores de idade (18 anos) podem recorrer ao Juizado de Pequenas Causas, enquanto pessoas jurídicas apenas comparecem na condição de réu. A discriminação fundamenta-se em três razões básicas: primeiro, para que se preserve a função estritamente popular do tribunal; segundo, para evitar o congestionamento da Corte que possivelmente ocorreria no caso de pessoas jurídicas poderem litigiar umas com as outras e contra pessoas físicas; terceiro, porque se parte do pressuposto de que pessoas jurídicas têm condições de arcar com os custos de um litígio promovido perante a corte comum.

A ação pode ser proposta, a critério do autor, perante o juizado do condado onde o réu resida, exerça emprego, ou conduza atividade comercial ou profissional. Desta forma, ainda que o reclamado tenha residência oficial fora de um dos cinco condados da cidade de Nova lorque, mas exerça atividade em qualquer deles, poderá ser ali acionado. Com isSo, a jurisdição do Juizado de Pequenas Causas é bastante ampla, abrangendo inclusive a população flutuante que diariamente se desloca para Nova lorque.
A assistência de advogado não é obrigatória. Ao contrátio, estimula-se a apresentação pessoal da causa como forma de aproximar a parte do julgador e permitir que este apreenda diretamente a questão em litígio. Em casos mais complexos, o próprio Tribunal recomenda à parte que recorra à assistência de profissional. Além disso, quando a questão envolve matéria de interesse público, poderá ser solicitada a participação de um advogado pro bono.

Na hipótese de autor e réu se fazerem representar por advogado, a causa poderá, a menos que haja acordo, ser transferida para a Corte Comum, no pressuposto de que ambas as partes têm condiç̃es econômicas para arcar com as despesas do litígio.

O Juiz e os árbitros devem, ao decidir, visar à 'justiça substancial' (substantial justice), de acordo com as regras de 'direito substantivo' (substantive law). Todavia, não estão adstritos às regras comuns de prova (rules of evidence), o que lhes permite tratar com grande flexibilidade a fase de conhecimento do processo e assegurar liberdade para julgar por convicção subjetiva.

O rito processual é simples, informal e essencialmente oral, o que não impede as partes de apresentarem razões por escrito, se assim desejarem. Não se formam autos, nem se transcrevem depoimentos das partes e testemunhas. Todas as anotações relevantes são feitas pelo Juiz ou pelo árbitro em simples fichas de registro.

$\mathrm{Na}$ alocação de tarefas entre o Juiz e os árbitros encontra-se a pedra de toque do sucesso do Juizado de Pequenas Causas, que explica a sua capacidade de julgar setenta mil casos anuais, apenas na cidade de Nova lorque. Cerca de oitocentos advogados de reconhecida capacidade profissional funcionam como árbitros sem qualquer remuneração.

O encaminhamento de uma causa ao árbitro depende do consenso das partes. Para tanto, o Juizado encarrega-se de demonstrar aos litigantes as vantagens de levarem a disputa a um árbitro que, além de amplamente capacitado para julgar, tem mais tempo de ouvir as partes e as testemunhase, se for o caso, examinar outras provas. Em geral, metade dos litígiosé submetida aos árbitros.

A decisão arbitral é irrecorrível e insuscetivel de revisão judicial. Isto porque se parte do pressuposto de que a opção pelo arbitramento tem força de conveção entre as partes e em renúncia ao direito de revisão judicial. Por outro lado, da decisão do Juiz cabe recurso. De qualquer forma, o número de recursos é insignificante (inferior a 1\% das decisões proferidas pelo Juiz). De fato o baixo valor de demanda e o rito sumaríssimo, do qual não se guardam registros detalhados, desencorajam o recurso. 
A própria disposição física do recinto do Tribunal estimula as partes a se encaminharem ao árbitro. Na sala principal de audiências, onde se encontra o Juiz presidente instalado no bench, o ambiente é solene (sem prejuízo da informalidade do processo) e grande o número de pessoas (todos os litigantes da mesma noite). Em pequenas salas adjacentes encontram-se os árbitros, sem platéia, os quais se sentam à mesma mesa que as partes. Não há outros funcionários da Corte presentes, com excecão de um guarda que auxilia o árbitro e, discretamente, se encarrega da boa ordem.

O número de árbitros varia de condado para condado, em função do volume de trabalho. 0 compromisso normal do árbitro é de comparecimento uma noite por semana. O exercício da função do árbitro tem amplo reconhecimento por parte da comunidade, inclusive da Ordem dos Advogados (Bar Association), não só pelo fato de ser trabalho gratuito, mas também pela boa qualidade do seu desempenho.

A solução da demanda por acordo é permanentemente estimulada pelo árbitro e, via de regra, parte significativa dos casos é resolvida por conciliação.

Para que se dê início ao processo, basta que o queixoso ou alguém em seu nome se dirija à secretaria do Juizado munido das informações essenciais sobre o caso e pague uma taxa de US\$3,40 (três dólares e quarenta centavos) e mais US\$ 1,40 (hum dólar e quarenta centavos) correspondente ao custo de remessa postal (carta registrada). O funcionário do Juizado transcreve, em ficha própria e em termos simples, concisos e em linguagem não técnica, as informações a ele transmitidas. A ficha é, a seguir, assinada pelo autor ou seu representante.

A data da audiência será obrigatoriamente marcada dentro de um prazo não inferior a quinze dias e não superior a trinta dias da apresentação da queixa. O mandado de citação (notice of claim), em formato padrão, reproduzirá os dados essenciais e o valor da postulação, além de ałguns esclarecimentos e observações necessários a orientar o réu. Ainda no mesmo ato da apresentação da queixa, o autor ou seu representante receberá notificação contendo a data e hora da audiência, bem como instruções sobre como proceder com relação às provas.

As queixas podem ser apresentadas durante o expediente normal da Corte e, em certos dias e condados, até às vinte e uma horas e trinta minutos.

A citação efetua-se por carta registrada, com aviso de recepção. O litígio considera-se instituído com a citação epistolar, ainda que o réu se recuse a assinar o aviso de recepção.
Na impossibilidade de se efetivar a citação por carta, o mandado de citação poderá ser entregue ao réu por qualquer pessoa, inclusive parente ou amigo do autor, com exceção dele próprio. Mediante pagamento de taxa extra, a citação poderá ser feita por oficial de justiça (process server).

O direito a reconvenção é assegurado ao réu, caso este se considere também legalmente qualificado para postular quantia que não exceda a mil dólares. Além disso, é possível o chamamento à lide de terceiro que o réu considere o verdadeiro responsável pela causa. Pode ainda o réu exigir julgamento perante o júri, caso em que deverá fornecer caução para pagamento da condenação, além de responder pelos honorários do próprio júri.

Réus pessoas jurídicas devem ser representados por diretor, sócio ou acionista majoritário. Associations, isto é, entidades que representam classes ou grupos, devem fazer-se representar obrigatoriamente por advogado.

Conforme se pôde verificar quando da visita pessoal ao Juizado de Pequenas Causas de Manhattan, são argüidos diversos incidentes processuais pelos réus e seus representantes (não recebimento de citação em tempo hábil, impossibilidade de convocar testemunhas ou produzir provas, pedidos de reconvenção, etc.). Essas argüições são apreciadas pelo Juiz de forma sumária e, via de regra, é concedido um único adiamento.

A revelia (defaut) não exime o autor de provar a procedência da sua queixa.

A sessão de audiência é iniciada pontualmente às dezoito horas e trinta minutos, com toda a solenidade comum aos Tribunais norte-americanos. A seguir o Juiz faz breve alocução explicando o funcionamento e os objetivos do Juizado de Pequenas Causas e convida as partes ao acordo ou, então, a que submetem o litígio à apreciação de um dos árbitros. O magistrado esclarece, ainda, que a opção pelo arbitramento implica em renúncia ao direito a recurso.

Enquanto o Juiz decide os incidentes processuais argüidos pelas partes (são gastos cinco minutos, em média, por argüição), um funcionário da Corte procede à chamada nominal das partes e as encaminha diretamente a um árbitro, caso as mesmas já se tenham posto de acordo quanto à submissão ao arbitramento.

O tempo despendido pelo árbitro, por assunto, varia de acordo com a complexidade da prova e a existência, ou não, de testemunha. Verificou-se que um dos árbitros gastava, em média, quinze minutos por caso. No dia seguinte à audiência, a decisão é comunicada aos litigantes pelo correio. Evitam-se, 
dessa forma, conflitos pessoais e apressa-se o encaminhamento das audiências. ${ }^{2}$

A natureza dos casos submetidos ao Juizado de Pequenas Causas reflete as mutações ocorridas na ordem econômica e social, bem como a evolução do sistema judiciário no sentido da maior especialização dos Tribunais e da simplificação de normas processuais. Cerca de metade das demandas submetidas à apreciação do Juizado de Pequenas Causas está hoje relacionada com infrações havidas na relação entre consumidores, de um lado, e comerciantes, fabricantes e prestadores de serviços, de outro ${ }^{3}$. Todos os assuntos pertinentes a locações são privativos do 'Juizado de Habitações' (Housing Part) e os litígios relacionados com danos materiais decorrentes de acidentes de trânsito reduziram-se bastante, em face da nova legislação sobre seguros que eliminou a 'culpa' como fator juridicamente relevante para a indenização.

O Juizado de Pequenas Causas não conta com meios específicos de execução dos seus julgados, cabendo ao próprio autor promovê-la. De posse da decisão favorável, o autor deverá comunicar o seu conteúdo ao réu, exigindo o pagamento. Decorridos dez dias da comunicação e não tendo havido liquidação do débito, o autor poderá recorrer ao sheriff ou ao marshall do condado, funcionários da municipalidade, ambos com poderes para efetivar a liquidação, que é, portanto, extrajudicial. 0 executante deverá indicar ao sheriff ou marshall os bens do devedor. A liquidação poderá dar-se mediante arresto, inclusive de conta bancária e do salário do devedor. Na hipótese de indenização decorrente do uso de veículo, é possível, ainda, solicitar a suspensão de licença de habilitação do executado até o pagamento da dívida.

O índice de decisões incobráveis é, na prática, bastante elevado e se constitui num dos pontos sensíveis da sistemática de tratamento judicial das pequenas causas.

A real dimensão da Small Claims Court não poderá ser apreciada fora do quadro evolutivo de todo o sistema judiciário de Nova lorque. A par do Juizado de Pequenas Causas, que funciona apenas à noite, há ainda duas importantes divisões da Corte Cível que complementam o trabalho daquele Juizado, a saber: a Day Time (smaln Part, que se ocupa de causas de valor até dez mil dólares e também adota procedimentos sumaríssimos, se bem que considerada parte integrante do Tribunal comum; a Housing Part, já mencionada, com jurisdição exclusiva sobre todas as matérias relativas a locações e moradia em geral.

Em ambas as divisões prevalece o mesmo sentido de induzir as partes a soluções amigáveis de. pendências. As causas de valor até seis mil dólares devem ser necessariamente submetidas a arbitramento na Day Time Part. O Juízo arbitral é composto de três árbitros, profissionais e remunerados, e as decisões são suscetíveis de recurso. A assistência por advogado é dispensável, se bem que em $90 \%$ das demandas haja participação desses profissionais.

O Juizado de Pequenas Causas surgiu, em Nova lorque, no ano de 1934, com a finalidade de julgar causas de valor inferior a cinqüenta dolares, sendo identificado inicialmente como a'corte do pobre' (poor man's court). Trata-se de evolução relativamente tardia, uma vez que a origem desse tipo de Juizado remonta o período de 1912-1916, quando um novo conceito de sistema judicial foi organizado em cidades dos Estados do Kansas, Oregon, Ohio e Illinois, como tentativa de transpor para as áreas urbanas algo semelhante à função desempenhada nas zonas rurais pelos Juízes de Paz. Por ser mais recente, o Juizado de Pequenas Causas de Nova lorque já se encontra escoimado das deficiências iniciais verificadas nas primeiras experiências de outros Estados.

O crescente congestionamento dos Tribunais comuns fez com que o Juizado de Pequenas Causas assumisse, gradativamente, papel fundamental no sistema judiciário norte-americano e, em particular, em Nova lorque. Nos últimos dez anos, graças à ampliação do conceito de 'pequenas causas' e à completa reformulação de toda a metodologia de funcionamento do aparelho judiciário do Estado, o Juizado de Pequenas Causas continuou a crescer em importância. Com jurisdição sobre causas de valor até mil dólares, esse juizado é hoje descrito como a 'Corte do homem comum' lcommon man's court).

\section{A Viabilidade do juizado de pequenas causas no Brasil}

A assimilação de institutos jurídicos e de sistemas judiciários estrangeiros é tarefa complexa, nem sempre viável, em face das peculiaridades culturais, políticas e econômicas de cada povo. Esses institutos e modelos têm, via de regra, raizes históricas longínquas, insuscetíveis de transposição direta de uma para outra ordem jurídica. No caso específico do Juizado de Pequenas Causas, o seu aproveitamento no Brasil se afigura menos dificil, por se tratar de experiência relativamente nova,desenvolvida a partir de condicionantes comuns, em grande parte, aos grandes centros urbanos, a saber: a elevada taxa de concentração populacional, a formação de bolsões de pobreza na área urbana, a intensificação dos conflitos individuais e a falta de acesso de parcela ponderável da população ao sistema judiciário, 
em face do congestionamento da Justiça e do alto custo da prestação jurisdicional. A experiência norte-americana demonstra, por outro lado, que o desenvolvimento do conceito de 'pequena causa' independe de alteração das normas de direito substantivo. Trata-se, tão somente, de aplicar o 'mesmo' direito de 'forma' diferente. Nem por isso a reforma do sistema judiciário e da processualística aplicável às causas de pequeno valor dispensa enfoque drasticamente distinto daquele que ainda prevalece no Brasil.

Os maiores obstáculos à implantação de um sistema judiciário simples, informal e acessivel, em país com características histórico-culturais do Brasil, são essencialmente de três ordens. Em primeiro lugar, a ausência de tradição no campo da composiçăo extrajudicial de conflitos, o que impede o desenvolvimento do arbitramento, tal como adotado pela Small Claims Court de Nova lorque. Em segundo lugar, o excessivo apego ao princípio de que nenhuma lesão de direito individual pode ser subtraída da apreciação pelo Poder Judiciário. Esse princípio, de inquestionável pureza conceitual, perde significado na medida em que, na prática, grande parte dos conflitos social e economicamente relevantes não pode ser levada ao conhecimento da Justiça, em face das limitações sócio-culturais e econômicas de ambas as partes ou de uma delas.

Em terceiro lugar, a padronização das normas de direito processual torna inelástica a adaptação do sistema judiciário às peculiaridades regionais. Por esse motivo, afigura-se causa aplicável uniformemente em todo o Brasil. É recomendável, pois, que se dê aos Estados certo grau de autonomia para legislar sobre matéria de processo.

Além disso, a forma mais ágil e sumária de procedimento previsto no Processo Civil Brasileiro é o 'procedimento sumaríssimo', que se constituiu, sem dúvida, numa importante inovação. Todavia, não vem ele funcionando a contento, sendo inúmeros os casos de não cumprimento do prazo legal de 90 dias para decisão. As causas principais do insucesso parcial do 'procedimento sumaríssimo' são, a meu ver, as seguintes:

a) o 'procedimento sumaríssimo' é adotado nos mesmos juízos já sobrecarregados de causas subordinadas aos demais ritos processuais, ordinários ou especiais, sendo impossível a designação de audiência de instrução e julgamento com a brevidade necessária. Em Comarcas maiores, os atrasos na marcação da audiência chega a um ano.

b) O 'procedimentò sumaríssimo' não impede a provocação, pelas partes, de diversos incidentes processuais, cuja solução dependente da prática de atos processuais solenes e formais, sem se estabele- cer rito sumaríssimo, também, para a decisão desses incidentes.

c) Ao contrário do que ocorre na sistemática do Juizado de Pequenas Causas, o 'procedimento sumaríssimo' não abrange a fixação do quantum da condenação, quando se trata de sentença sujeita a liquidação.

Impõe-se, portanto, prever uma forma especial de procedimento sumaríssimo que simplifique todo o processo de instrução e julgamento do litígio, compreendendo, não só o seu mérito, como ainda qualquer incidente processual, bem como a fixação do valor líquido do julgado.

A par do aperfeiçoamento do Código de Processo Civil, relativamente ao desenvolvimento do processo sumaríssimo, é de toda conveniência que se idealize um procedimento especialíssimo que só seria aplicável em causas de valor econômico reduzido, dimensionável em dinheiro.

Nestes casos específicos, poder-se-iam abandonar os princípios gerais estabelecidos pelo Código de Processo Civil para instrução e julgamento de causas mais relevantes, proporcionando às partes Justiça bem mais barata, sem prejuízo das garantias fundamentais de defesa dos direitos do autor ou do réu.

Os princípios fundamentais, que devem orientar o desempenho do Juizado de Pequenas Causas, são os seguintes:

Oralidade - Todos os atos processuais devem ser orais e desenvolvidos numa única audiência de instrução e julgamento, na qual serão debatidase decididas todas as questões alegadas pelas partes, inclusive as preliminares ou prejudiciais de mérito.

Facultatividade - O processo, perante o Juizado especial, deve ser facultativo, assegurando-se ao autor da ação o direito de postular no Juízo comum. A escolha, contudo, dependerá da manifestação exclusiva do autor, não sendo permitido ao réu impugná-la.

Competência limitada - O Juizado especial deve ser competente para processar e julgar unicamente causas de valor econômico reduzido e, dentre estas, só as que visarem à condenção do réu ao pagamento de quantia certa, não superior a determinado limite.

Proibição de intervenção de terceiros - Não se deve admitir, no processo sumaríssimo do Juizado especial, qualquer forma de intervenção de terceiros, salvo o litisconsórcio necessário. A sentença não deve produzir efeitos em relação a terceiros, nem para prejudicá-los, nem para beneficiá-los, devendo limitar-se a decidir a controvérsia, sempre de 
cunho patrimonial, entre autor e réu. O litisconsórcio ativo ou passivo somente será admitido se o autor o requerer, ao formular o pedido inicial.

Assistência facultativa por advogado - A assistência por advogado deve ser facultativa, tanto para não onerar as partes, como para permitir ao julgador o contato direto com os litigantes.

Funcionamento descentralizado - Na medida do possível, o Juizado especial deve situar-se geograficamente próximo das partes e funcionar fora do expediente normal de trabalho.

Adoção do pacto arbitral - Caso as partes aceitem espontaneamente a apresentação do litígio à decisão arbitral, desta decisão não cabe recurso.

\section{Notas}

1. Palestra proferida na Universidade de Brasília, em 3 de junho de 1981, no Seminário sobre Desburocratização do Judiciário.

2. Na noite do dia 18 de setembro de 1980 , o Juizado de Manhattan estava particularmente congestionado, tendo nada menos que cento e noventa casos em pauta.

3. A maioria dos cento e noventa casos submetidos ao Juizado na noite do dia 18 de setembro, em Manhattan, estava relacionada com venda de produtos defeituosos, extravio de bagagem por companhias aéreas e danos resultantes da negligência na prestação de serviços. 